\title{
ANALYZING PUBLIC TRAVEL DEMAND BY A FUZZY ANALYTIC HIERARCHY PROCESS MODEL FOR SUPPORTING TRANSPORT PLANNING
}

\author{
Ahmad ALKHARABSHEH, Sarbast MOSLEM, Szabolcs DULEBA* \\ Dept of Transport Technology and Economics, Budapest University of Technology and Economics, Hungary
}

Submitted 12 June 2019; resubmitted 17 November 2019; accepted 5 February 2020;

first published online 17 January 2022

\begin{abstract}
Travel demand plays an essential role in strategic transport planning. Generally, experts use either discrete methods, e.g. discrete choice models or simulation, e.g. activity-based models to estimate demand in transportation. This paper offers a different solution; instead of using the traditional approach, the demand is considered as a Multi Criteria Decision Making (MCDM) problem and surveying the citizens' preferences provides the results for decision support. Public transport demand depends on two main issues, quality and price of the transportation. In a hierarchical model, both issues have been integrated and the well-proven Analytic Hierarchical Process (AHP) method has been applied in the current research. Further, fuzzyfication of the scores have also been conducted because of the citizen evaluator pattern. The fuzzyAHP (FAHP) model has been tested in a real-world situation with the case study of Amman (Jordan).
\end{abstract}

Keywords: public transport, travel demand, multi criteria decision making (MCDM), fuzzy-AHP (FAHP), transport planning, questionnaire survey.

\section{Notations}

3PL - third-party logistics;

AHP - analytic hierarchy process;

$\mathrm{CR}$ - consistency ratio;

FAHP - fuzzy-AHP;

MCDM - multi criteria decision making;

$\mathrm{O}-\mathrm{D}$ - origin-destination;

PC - pairwise comparison;

SEM - structural equation model;

SERVQUAL - service quality (multidimensional research instrument);

TOPSIS - technique for order of preference by similarity to ideal solution;

WTP - willingness to pay.

\section{Introduction}

Travel demand analysis and forecasting is a major issue in the transportation discipline and this topic continues to receive extra attention both in academic research and applied transportation planning (Rasouli, Timmermans 2012).
There are three main directions in travel demand modelling: (1) the four-step models, (2) discrete choice models and (3) activity-based models.

The four-step models integrate four phases of travel demand determination: (1) trip generation, (2) trip distribution, (3) modal split and (4) trip assignment (McNally 2007). The unit of these models is a trip conducted by individuals and these trips are aggregated for the ultimate determination of the demand. O-D matrices, regression analysis, logit models and assignment algorithms are applied in these types of models.

Discrete choice modelling applies most commonly the random utility theory to predict the choice of discrete responses, e.g. mode choice, destination choice. Each single travel choice is considered as a utility maximization behaviour (Bhat 2018) in which the utility function has a deterministic and a random component (Hasnine, Habib 2018). Then these single choices are aggregated, which results in the total travel demand. Activity-based models assume that travel demand consists of trips, which have been initiated by activities that determine the destination,

*Corresponding author. E-mail: duleba.szabolcs@mail.bme.hu 
time, frequency, etc. (Bowman, Ben-Akiva 2001). A significant part of these models apply micro-simulation for individuals and then simulate the total travel demand of a city based on the activity types, activity durations, destinations and mode choice (Pendyala et al. 2005).

Our paper use a different approach. We consider public travel demand as the aggregation of citizen preferences related to the quality and price of the trips. It has to be emphasized that this approach has a priori advantages and shortcomings compared to the traditional models. Evidently, this consideration is not capable of determining the current or forthcoming quantity of public travels. In addition, the motivations of travel, just as activity-based applications, are not detected. Moreover, this type of methodology cannot compute the elasticity of the utility curves of the individuals or groups, thus cannot define demand curves or functions. However, the MCDM modelling has significant benefits in the relation of other demand modelling. By the application of the proposed methodology, it is possible to gain valuable information on users' attitude to quality and price elements of public transportation. The evaluation of service elements and expressing the preference of improvements including the price, reflect the travel demand indirectly and support strategic decision related to increasing this demand. AHP provides a clear overview on the decision (demand) elements so it is well-applicable in questionnaire based passenger surveys.

Applying fuzzyfication has a significant role in this research. Since the evaluators are citizens, so layman, their scoring in the questionnaire survey cannot be considered as trustworthy as expert evaluations. Consequently, except for the consistency check of AHP, the risk of potentially biased scoring is mitigated by allowing slight modifications of the scores by the fuzzy approach.

The rest of the paper is structured as follows: first, the literature review of public transport quality elements and price is demonstrated followed by the methodology section, which introduces the applied model. Further, a short description of the examined city and the results of the empirical case study on the public transport situation of the capital of Jordan, Amman is presented and finally some general and specific conclusions are drawn.

\section{Literature review}

The choice of public transport as a preferred mode of travel by travellers in the city is mainly influenced by the quality of public transportation operation services, precisely the bus operation service. In the eighties and nineties, the satisfaction of the users was acceptable for the basic services and the availability of routes and the location of service (Rohani et al. 2013). However, passengers today are more demanding from the operators including fast, reliable, safe service, short walking distances, low floor buses, cheaper service, sustainable, and friendly safe drivers. Providers are responding to such demands seeking to increase their revenue, boost the number of customers, and the company's profit (Rohani et al. 2013).
Nowadays, service coverage, frequency of services, hours of services, and service reliability are the main attributes of the bus service quality. There are several aspects that need to be considered when modelling the quality and satisfaction of the consumers of a service in order to design efficient improvements. First of all, quality can be analysed from two aspects (Paquette et al. 2012): (1) the perceived quality resulting from the personal experience of the users and (2) the expected quality, which determines what the users would desire from an efficient public transport service (Eboli, Mazzulla 2008).

Redman et al. (2013) mentioned other possible techniques to enhance and develop public transportation quality in passenger perceptions, while Mokonyama and Venter (2013) evaluated how different packages of public transportation service will affect the customer satisfaction. Hine and Scott (2000) considered the preferences of public transport customers for the way of travel that they chose. Similarly, Pantouvakis and Lymperopoulos (2008) assessed the importance of the physical elements of services on passenger satisfaction. Del Castillo and Benitez (2012) examined the quality of public transportation services. Taking a different view, Lai and Chen (2011) determined the particular factors influencing behavioural intentions of public transit passengers using SEM for describing customer satisfaction. SEM methodology is widely applied in transport planning and can be considered as contrast of the MCDM techniques, since in SEM, the travel choice is examined by econometric tools, while in MCDM the choice is a decision made by citizens (Eboli, Mazzulla 2007). Consequently, in SEM the rationality of the real or potential passengers is assumed, while in MCDM rationality is not a pre-condition, however, the consistency of the responses is checked. Other approaches also exist, by a behavioural intention model, Lai and Chen (2011) examined passenger perception of electronic service quality. Within a multistage structure in passenger transportation, Chiou and Chen (2012) stated that a lack of satisfaction at a particular stage would affect customer perception of the consequent service stage.

Analysing and determining customer satisfaction and demand can also be approached as a decision problem (Pantouvakis, Lymperopoulos 2008). Assessing all service quality elements with price into a hierarchical structure and surveying citizens on their preferences (Moslem, Duleba 2019) might help the local government in making their decisions related to the urban transportation system. The hierarchical structure provides the opportunity to apply a well-proven and popular MCDM methodology, the AHP and its extension, the FAHP. Using the FAHP - AHP with other integrated models are being used widely in the transportation field and other fields to support the decision makers in the designated fields. For instance, Ngossaha et al. (2017) used FAHP to conduct a framework allows the decision maker to choose the most eco-responsible policy among other alternatives, Park et al. (2018) conducted an evidence-based approach to analyse priority factors during the acquisition of second-hand ships from 
the angle of shipping corporations, while Ruiz-Padillo et al. (2018) assessed neighbourhoods by evaluating the walkability problems.

Gao et al. (2018) evaluated the competitiveness of a Chinese port based on related criteria, the study focused on the future strategic plans' Chinese ports. Arslan (2009) presented a new decision support model for the implementation of appropriate transportation projects by using FAHP approach, the research found that this model is reasonable and can employ for achieving public idea regarding on transportation projects in the development and planning steps.

Lupo (2013) used the FAHP in public transportation field to conduct a methodology based on extended of SERVQUAL for analysis of performance in public transport service, as a result of the research showed that the perception of management of service quality positively influence of all levels of service performance. Liou et al. (2008) and Liou, Chuang (2010) and assessed the name and company image in airline market. Consequently, the results showed that that service emerge, and safety record square measure the numerous factors within the transport market. Teng et al. (2010) has used FAHP in the transportation construction projects to allocate budget for a transport projects, the result evinced that the proposed pattern can divide objectives of the transportation sector and real demands in the different demand levels. Lirn et al. (2003) - the lack in previous studies, which did not emphasize on selection of transhipment led to use the FAHP to identify the significant criteria for selection of transhipment port, and the outcome of this paper conclude that the port geographical location is the best criteria selection of transhipment port.

There are also examples in which other methods are attached to FAHP models to make the decision analysis complete. Bilişik et al. (2013) examined the service quality in public transportation due to solve various issues, led to evaluate the customer satisfaction based on SERVQUAL measurement by using the FAHP and fuzzy-TOPSIS approach, as an outcome it was noticed that the fee and tangibles factors are the greatest weights in evaluation of service quality. As well as, because of the selection of $3 \mathrm{PL}$ service providers is complex decision with uncertainty, FAHP and fuzzy-TOPSIS has been used to present a new decision support tool for evaluation of 3PL transportation (Yayla et al. 2015). Results of this research indicated that proposed model can reflects forecasting of 3PL transportation service provider. While John et al. (2014) used TOPSIS and FAHP to select an appropriate model for evaluation of performance efficiency in seaports, the outcome of this study showed that increasing reliability is the best investment strategy.

\section{Methodology}

The conventional AHP is a well-proven decision making methodology, which was enhanced by T. L. Saaty in 1980s to simplify the complex decision problems (Saaty
1980). The AHP method is based on an additive weighting process, in which several relevant criteria are represented through their relative importance. AHP approach was extensively applied by academics and professionals in many fields and problems, mainly in engineering fields like transport engineering field (Farooq et al. 2019; Ghorbanzadeh et al. 2019; Duleba, Moslem 2018; Chowdhury et al. 2018; Balaji et al. 2019; Duleba et al. 2012, 2013), in construction engineering field (Kumar et al. 2018; Hatefi, Tamošaitienè 2018), in architecture (Abastante et al. 2018; Haghighathoseini et al. 2018) and in many different engineering fields (Gupta 2018; Murat et al. 2016; Tan et al. 2014). However, AHP approach has some restrictions and to overcome these limitations many researchers integrate fuzzy theories with AHP approach for providing more reliable and robust results (Chen et al. 2018; Grošelj, Zadnik Stirn 2018; Park et al. 2018).

In this study, the FAHP approach is applied to prioritize and rank the identified public bus transport supply quality criteria in Amman. Consequently, the FAHP approach was used to fuzzify the hierarchical analysis by allowing fuzzy numbers for the PCs of the evaluators. The hierarchy tree is subject to establish PCs among the 4 main criteria and 24 sub-criteria. After collecting the data, the geometric mean approach was used for aggregating evaluators' response and the final scores were computed and prioritized. In order to ensure the quality and trustworthy of collected data, the consistency check was accomplished.

The mathematic notion for the FAHP evaluation was used from the work of Sun (2010). In the referred paper, the author conducted a fuzzy logic technique by developing a questionnaire survey with triangular fuzzy numbers scales. The following formulas are merely applications in our research for the newly created integrative decision model. We introduce the formulas in detail in order to give insight to the computational process.

A fuzzy number $\tilde{A}$ on $\mathbb{R}$ to be a triangular fuzzy number if its membership function $\mu_{\tilde{A}}(x): \mathbb{R} \rightarrow[0,1]$ is equal to the consequential Equation (1):

$$
\mu_{\tilde{A}}(x)= \begin{cases}\frac{x-d}{m-d}, & d \leq x \leq m ; \\ \frac{h-x}{h-m}, & m \leq x \leq h ; \\ 0, & \text { otherwise. }\end{cases}
$$

From Equation (1), $d$ and $u$ intend the inferior and superior bounds of the fuzzy number $\tilde{A}$, and $m$ is the modal value for $\tilde{A}$ (Figure 1). The triangular fuzzy number can be exhibited by $\tilde{A}=(d, m, h)$.

The operational laws of triangular fuzzy number $\tilde{A}_{1}=\left(d_{1}, m_{1}, h_{1}\right)$ and $\tilde{A}_{2}=\left(d_{2}, m_{2}, h_{2}\right)$ are blazon as consecutive formulas as addition (Equation (2)), multiplication (Equation (3)), subtraction (Equation (4), division (Equation (5)) and reciprocal (Equation (6)) of the fuzzy numbers. In our computational procedure all formulas were applied. 


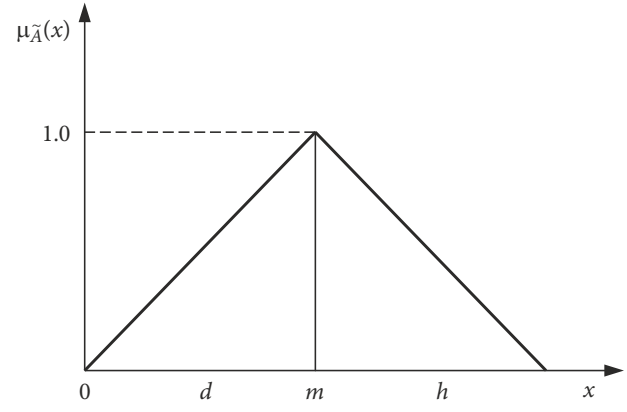

Figure 1. The membership functions of the triangular fuzzy number

The following equation shows the addition of fuzzy number $\oplus$ :

$$
\begin{aligned}
& \tilde{A}_{1} \oplus \tilde{A}_{2}=\left(d_{1}, m_{1}, h_{1}\right) \oplus\left(d_{2}, m_{2}, h\right)= \\
& \left(d_{1}+d_{2}, m_{1}+m_{2}, h_{1}+h_{2}\right) .
\end{aligned}
$$

The following equation shows the multiplication of fuzzy number $\otimes$ :

$$
\begin{aligned}
& \tilde{A}_{1} \otimes \tilde{A}_{2}=\left(d_{1} \cdot d_{2}, m_{1} \cdot m_{2}, h_{1} \cdot h_{2}\right) \text { for } \\
& d_{1}, d_{2}>0 ; m_{1}, m_{2}>0 ; h_{1}, h_{2}>0 .
\end{aligned}
$$

The following equation shows the subtraction of fuzzy number $\ominus$ :

$$
\begin{aligned}
& \tilde{A}_{1} \ominus \tilde{A}_{2}=\left(d_{1}, m_{1}, h_{1}\right) \ominus\left(d_{2}, m_{2}, h_{2}\right)= \\
& \left(d_{1}-h_{2}, m_{1}-m_{2}, h_{1}-d_{2}\right) .
\end{aligned}
$$

The following equation shows the division of fuzzy number $\varnothing$ :

$$
\begin{aligned}
& \tilde{A}_{1} \varnothing \tilde{A}_{2}=\left(\frac{d_{1}}{h_{2}}, \frac{m_{1}}{m_{2}}, \frac{h_{1}}{l_{2}}\right) \text { for } \\
& d_{1}, d_{2}>0 ; m_{1}, m_{2}>0 ; h_{1}, h_{2}>0 .
\end{aligned}
$$

The following equation shows the reciprocal of fuzzy number:

$$
\begin{aligned}
& \tilde{A}^{-1}=\left(d_{1}, m_{1}, h_{1}\right)^{-1}=\left(\frac{1}{h_{1}}, \frac{1}{m_{1}}, \frac{1}{d_{1}}\right) \text { for } \\
& d_{1}, d_{2}>0 ; m_{1}, m_{2}>0 ; h_{1}, h_{2}>0 .
\end{aligned}
$$

In the incumbent research, the computational technique was based on the sequent fuzzy numbers that was defined by Taskin Gumus (2009) and Sun (2010) in Table 1.

Table 1 . The scale of fuzzy numbers and their linguistic scale

\begin{tabular}{|c|l|c|}
\hline $\begin{array}{c}\text { Fuzzy } \\
\text { number }\end{array}$ & \multicolumn{1}{|c|}{$\begin{array}{c}\text { Linguistic } \\
\text { scale }\end{array}$} & $\begin{array}{c}\text { Scale of fuzzy } \\
\text { number }\end{array}$ \\
\hline 1 & equal & $(1,1,1)$ \\
\hline 2 & weak advantage & $(1,2,3)$ \\
\hline 3 & not bad & $(2,3,4)$ \\
\hline 4 & preferable & $(3,4,5)$ \\
\hline 5 & good & $(4,5,6)$ \\
\hline 6 & fairly good & $(5,6,7)$ \\
\hline 7 & very good & $(6,7,8)$ \\
\hline 8 & absolute & $(8,9,9)$ \\
\hline 9 & perfect & \\
\hline
\end{tabular}

The employed PC matrices were constructed based on the hierarchical structure of criteria as shown in Figure 2. Linguistic terms were assigned to the PCs by asking which criteria is more treasured than the other with respect to the main goal. As $\tilde{A}$ the biggest matrix $(5 \times 5)$ in the study so we demonstrate the fuzzyfication of the scale values for this case:

$$
\begin{aligned}
& \tilde{A}=\left[\begin{array}{lllll}
1 & \tilde{a}_{12} & \tilde{a}_{13} & \tilde{a}_{14} & \tilde{a}_{15} \\
\tilde{a}_{21} & 1 & \tilde{a}_{23} & \tilde{a}_{24} & \tilde{a}_{25} \\
\tilde{a}_{31} & \tilde{a}_{32} & 1 & \tilde{a}_{34} & \tilde{a}_{35} \\
\tilde{a}_{41} & \tilde{a}_{42} & \tilde{a}_{43} & 1 & \tilde{a}_{45} \\
\tilde{a}_{51} & \tilde{a}_{52} & \tilde{a}_{53} & \tilde{a}_{54} & 1
\end{array}\right]= \\
& {\left[\begin{array}{lllll}
1 & \tilde{a}_{12} & \tilde{a}_{13} & \tilde{a}_{14} & \tilde{a}_{15} \\
\frac{1}{\tilde{a}_{12}} & 1 & \tilde{a}_{23} & \tilde{a}_{24} & \tilde{a}_{25} \\
\frac{1}{\tilde{a}_{13}} & \frac{1}{\tilde{a}_{23}} & 1 & \tilde{a}_{34} & \tilde{a}_{35}
\end{array}\right],} \\
& \frac{1}{\tilde{a}_{14}} \frac{1}{\tilde{a}_{24}} \frac{1}{\tilde{a}_{34}} 1 \quad \tilde{a}_{45} \\
& \frac{1}{\tilde{a}_{15}} \frac{1}{\tilde{a}_{25}} \frac{1}{\tilde{a}_{35}} \frac{1}{\tilde{a}_{45}} 1
\end{aligned}
$$

where:

$$
\tilde{a}_{i j}= \begin{cases}a, & j \neq i \\ 1, & j=i,\end{cases}
$$

where:

$$
\begin{aligned}
& a=\tilde{9}^{-1}, \tilde{8}^{-1}, \tilde{7}^{-1}, \tilde{6}^{-1}, \tilde{5}^{-1}, \tilde{4}^{-1}, \tilde{3}^{-1}, \tilde{2}^{-1}, 1^{-1}, \\
& \tilde{1}, \tilde{2}, \tilde{3}, \tilde{4}, \tilde{5}, \tilde{6}, \tilde{7}, \tilde{8}, \tilde{9} .
\end{aligned}
$$

For accumulating the fuzzy weights for each rater group, the fuzzy geometric mean technique was implemented (Hsieh et al. 2004; Moslem et al. 2019):

$$
\begin{aligned}
& \tilde{r}_{i}=\left(\tilde{a}_{i 1} \otimes \tilde{a}_{i 2} \otimes \tilde{a}_{i 3} \otimes \tilde{a}_{i 4} \otimes \tilde{a}_{i 5}\right)^{\frac{1}{n}} ; \\
& \tilde{w}_{i}=\tilde{r}_{i}\left[\tilde{r}_{1} \oplus \tilde{r}_{2} \oplus \tilde{r}_{3} \oplus \tilde{r}_{4} \oplus \tilde{r}_{5}\right]^{-1},
\end{aligned}
$$

where: $\tilde{a}_{i j}$ is fuzzy comparison value of dimension $i$ to criterion $j ; \tilde{r}_{i}$ is a geometric mean technique of fuzzy comparison value of criterion $i$ to each criterion; $\tilde{w}_{i}$ is the fuzzy weight of the $i$ th criterion, which is illustrated by a triangular fuzzy number, $\tilde{w}_{i}=\left(d \cdot w_{i}, m \cdot w_{i}, h \cdot w_{i}\right)$; the $u \cdot w_{i}$, $m \cdot w_{i}$, and $l \cdot w_{i}$ emblematize the upper, middle, and lower values of the fuzzy weight of the $i$ th dimension.

The CR for all PC matrices was smaller than 0.1, which is acceptable to complete the FAHP analysis as Saaty (1977) suggested. The final scores of the proper eigenvectors provide the opportunity to set up a rank order of preferences for the participants of public bus transport on the issues of the system also considering the weights of the previous levels by using the following equation:

$$
\tilde{w}_{A_{i}}=\frac{\tilde{w}_{j}}{\tilde{w}} \cdot \frac{\tilde{w}_{i j}}{\sum_{k=1}^{n} \tilde{w}_{i k}}=\left(\frac{\tilde{w}_{j}}{\tilde{w}} \cdot \frac{1}{\sum_{k=1}^{n} \tilde{w}_{i k}}\right) \cdot \tilde{w}_{i j},
$$


where: $i=1, \ldots, n ; j=1, \ldots, m ; \tilde{w}=\sum_{i=1}^{m} \tilde{w}_{j} ; \tilde{w}_{j}>0 j=1$, ..., $m$ represents the related weight coordinate from the previous level; $\tilde{w}_{i j}>0 i=1, \ldots, n$ is the eigenvector computed from the matrix in the current level; $\tilde{w}_{A i} i=1, \ldots, n$ is the calculated weight score of current level's elements.

\section{Case study}

Amman, the capital of Jordan, is a growing town with associate degree calculable population of over three million citizens. The speedy growth is predicted to continue in the forthcoming years and might reach 6. 4 million inhabitants by the year 2025 (GAM 2010). Approximately 56\% of Amman's population is beneath the age of 25 (DoS 2017), because of that, there is an oversized range of scholars in colleges, colleges, and universities. The median annual household income of the city's residents is estimated at 5200 Jordanian Dinars (JoD) (GAM 2010), of which approximately $750 \mathrm{JoD}$, or $14 \%$, is annually spent on transportation.

This latter number has been increasing over the past few months, following the government's decision since 2008 to lift its subsidies on fuel, and periodically revise fuel prices in Jordan to reflect worldwide market prices. The city's rising and unplanned populated area has resulted in reduced transport quality and accessibility, increased traffic jams, and weakened the insufficient public transport systems. It is worth mentioning additionally the undesirable negative environmental (both noise and pollution) and safety impacts related to inflated vehicle traffic.

The public transport fleet in national capital consists principally of littler vehicles operated by either freelance operators or small firms. The fleet combine consists of buses, minibuses (or coasters), jitneys (fixed-route taxis), or regular taxis. Table 2 presents a breakdown of the fleet composition, still because the variety of operators and routes. As are often seen from Table 2, there is a comparatively sizable amount of normal (yellow) taxis in national capital. These taxis are considered fairly cheap and are often used as a commuter mode, contrary to what is the case in many other cities worldwide. Table 2 conjointly shows that jitneys area unit run on associate degree owner-operator basis.

Table 2. Fleet composition of Amman's public transport system (Imam 2014)

\begin{tabular}{|l|c|c|c|}
\hline \multicolumn{1}{|c|}{ Type } & Operators & Vehicles & Routes \\
\hline Buses & 15 & 470 & 96 \\
\hline $\begin{array}{l}\text { Minibuses } \\
\text { (coasters) }\end{array}$ & 307 & 440 & 148 \\
\hline Jitneys & 3215 & 3257 & 70 \\
\hline $\begin{array}{l}\text { Regular } \\
\text { taxis }\end{array}$ & 280 & 10636 & - \\
\hline
\end{tabular}

\section{Results}

In the research, meetings and discussions have been held in order to develop a model that may acquire the passenger's preferences in a simple manner, Figure 1 exhibits the model. Consequently, field survey has been conducted to gather the customers preferences, 100 participants involved in the survey on March 2019, and the sample of the participants was indiscriminately hand-picked from the public users (employee's, school students, and university students) as well as from different age layers so young and old people were included, gender was considered as well. However, places with the highest density from bus demand point of view: Jordan University, Sweileh, Al-Abdali, Al-Dakheliah roundabout, and Al-Mahatah bus stations were included in the survey to cover as more as possible responses and different preference's by the passengers for different locations inside Amman. 45 women with different age layer participated in the survey and 55 men participated as well. Cooperation has been experienced from the passengers to share their preferences. The average filling time of the survey was 20 to 25 min per young passenger and 30 to $35 \mathrm{~min}$ per old people passengers.

In our created model, altogether, 28 elements of travel demand (as depicted in Table 3) were assessed to examine elements of passenger preferences and attitude towards fare in public bus transport. This model can be considered as the most innovative part of our research, since it is the first MCDM model for transport integrating quality and price elements of travel demand.

Further, the transport demand criteria have been structured into a hierarchy, on one hand due to the better overview of the researchers and participants, on the other hand because of the requirements of the applied FAHP.

The hierarchical structure of the criteria determines the survey process, in which pair wise comparisons are required from the evaluators among the criteria situated in the same branch of the decision criteria tree. Participants have to compare pair wisely the demand importance of "service quality", "transport quality", "tractability" and "fare" on the level 1 for all possible pairs (Figure 2).

The typical comparison question is: how much more important is in your demand the "service quality" of public transport than the "transport quality"? The logic of the survey is the same for all other levels.

Having gained all scores from the evaluators, following the FAHP methodology, fuzzy-PCs have to be created for all branches of the decision structure as demonstrated below (Tables 4-10), where the results are aggregated for all evaluators. As shown in the tables, the fuzzy weight scores of all criteria in all levels are expressing three different scenarios as minimum, medium and maximum values. A score below 1 indicates real evaluations between 0 (expressing neutral relation between the two decision criteria) and 1, which means a slight superiority of one criterion over another and so forth. For instance "service 
Table 3. The applied transport demand elements and their short explanations

\begin{tabular}{|c|c|}
\hline $\begin{array}{c}\text { Applied transport } \\
\text { demand element }\end{array}$ & Short explanation \\
\hline Service quality & $\begin{array}{l}\text { all service excluding transport services on } \\
\text { the vehicle and information service }\end{array}$ \\
\hline Transport quality & $\begin{array}{l}\text { all service during the time spent on the } \\
\text { public vehicle }\end{array}$ \\
\hline Tractability & $\begin{array}{l}\text { the provided information about the } \\
\text { journey }\end{array}$ \\
\hline Physical comfort & $\begin{array}{l}\text { comfort of seats, physical space in the } \\
\text { bus, air conditioning }\end{array}$ \\
\hline Mental comfort" & $\begin{array}{l}\text { environmental aspects, behaviour of } \\
\text { driver and other passengers }\end{array}$ \\
\hline Safety of travel & $\begin{array}{l}\text { perception of safety, security of the } \\
\text { journey }\end{array}$ \\
\hline Perspicuity & $\begin{array}{l}\text { clear understanding of schedule and } \\
\text { information }\end{array}$ \\
\hline $\begin{array}{l}\text { Information } \\
\text { before travel }\end{array}$ & $\begin{array}{l}\text { amount and quality of information } \\
\text { previously of the journey }\end{array}$ \\
\hline $\begin{array}{l}\text { Information } \\
\text { during travel }\end{array}$ & $\begin{array}{l}\text { availability and quality of information on } \\
\text { the vehicle }\end{array}$ \\
\hline Approachability & $\begin{array}{l}\text { service before starting the travel, accessing } \\
\text { the lines }\end{array}$ \\
\hline Directness & $\begin{array}{l}\text { reaching the destination without shifting } \\
\text { vehicles }\end{array}$ \\
\hline Time availability & the time frame when using certain vehicle \\
\hline Speed & speed of the whole travel process \\
\hline Reliability & on time arrivals, keeping the schedule \\
\hline Distance to stops & reaching the starting bus stop \\
\hline Safety of stops & $\begin{array}{l}\text { the security of bus stops in terms of road } \\
\text { safety }\end{array}$ \\
\hline Comfort in stops & $\begin{array}{l}\text { roof, heating and cooling systems, seats of } \\
\text { the stops }\end{array}$ \\
\hline Need of transfer & $\begin{array}{l}\text { the need to change vehicles to the } \\
\text { destination }\end{array}$ \\
\hline Fit connection & $\begin{array}{l}\text { on time connection between bus lines or } \\
\text { between other type of public transport } \\
\text { (trains) }\end{array}$ \\
\hline $\begin{array}{l}\text { Frequency of } \\
\text { lines }\end{array}$ & $\begin{array}{l}\text { scheduled and realized frequency of the } \\
\text { buses }\end{array}$ \\
\hline $\begin{array}{l}\text { Limited time of } \\
\text { use }\end{array}$ & $\begin{array}{l}\text { the time frame between the first and the } \\
\text { last line of the day }\end{array}$ \\
\hline Journey time & $\begin{array}{l}\text { time spent on the vehicle, (get on_ get } \\
\text { off) }\end{array}$ \\
\hline Awaiting time & awaiting time for the proper line \\
\hline $\begin{array}{l}\text { Time to reach } \\
\text { stops }\end{array}$ & time to reach the departure bus stop \\
\hline Fare & $\begin{array}{l}\text { the money paid for a journey or a trip on } \\
\text { public transport }\end{array}$ \\
\hline $\begin{array}{l}\text { Price of one-way } \\
\text { tickets }\end{array}$ & the amount of money for one journey \\
\hline $\begin{array}{l}\text { Price of weekly/ } \\
\text { monthly tickets }\end{array}$ & $\begin{array}{l}\text { the amount of money for the weekly or } \\
\text { monthly trips }\end{array}$ \\
\hline $\begin{array}{l}\text { Discounted } \\
\text { tickets for } \\
\text { pensioners or } \\
\text { students }\end{array}$ & lower fare for pensioners or students \\
\hline
\end{tabular}

quality" (C1) is slightly inferior to "transport quality" (C2) considering the fuzzy aggregation of the evaluation scores, in case of the first scenario this produces a value of 0.94 as minimum, in the case of the maximum scenario, its value is 1.226 .

Afterwards, the final scores can be computed by conducting the eigenvector method of the AHP technique. Deriving eigenvector scores and then computing the weight scores enable us to determine the importance of each element in the decision structure in the decision, in our case in transport demand of the respondents. The higher score means the higher importance attached to each demand element. The order of scores implies ranking of importance, which is a significant support about travel demand for transport planners.

The priority order of different criteria in public bus transportation systems in terms of their development is presented in Table 11.

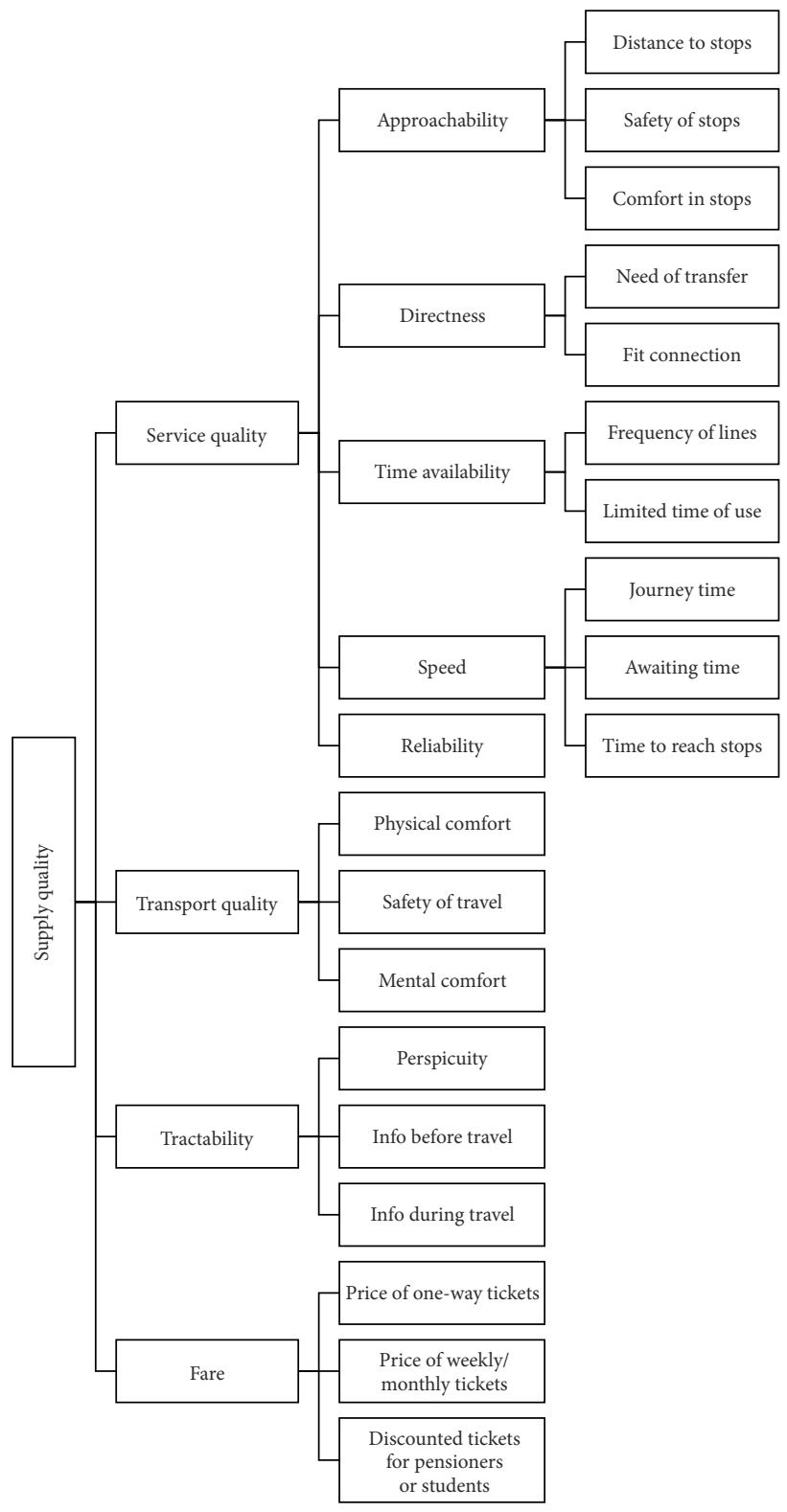

Figure 2. Elements of travel demand in a hierarchical structure 
Table 4. Fuzzy comparison matrix $(4 \times 4)$ for the factors in level 1

\begin{tabular}{|c|c|c|c|c|c|c|c|c|c|c|c|c|}
\hline Factor & \multicolumn{3}{|c|}{$\mathrm{C} 1$} & \multicolumn{3}{|c|}{$\mathrm{C} 2$} & \multicolumn{3}{|c|}{ C3 } & \multicolumn{3}{|c|}{ C4 } \\
\hline $\mathrm{C} 1$ & 1 & 1 & 1 & 0.8157 & 0.9246 & 1.0638 & 1.1136 & 1.2999 & 1.5185 & 1.0057 & 1.1661 & 1.3558 \\
\hline $\mathrm{C} 2$ & 0.9400 & 1.0816 & 1.2260 & 1 & 1 & 1 & 1.5918 & 1.8707 & 2.1585 & 1.5190 & 1.7684 & 2.0399 \\
\hline C3 & 0.6586 & 0.7693 & 0.8980 & 0.4633 & 0.5346 & 0.6282 & 1 & 1 & 1 & 0.7598 & 0.8739 & 1.0023 \\
\hline $\mathrm{C} 4$ & 0.7376 & 0.8576 & 0.9943 & 0.4902 & 0.5655 & 0.6583 & 0.9977 & 1.1443 & 1.3162 & 1 & 1 & 1 \\
\hline
\end{tabular}

Table 5. Fuzzy comparison matrix $(5 \times 5)$ for sub-factors in level 2 (service quality branch)

\begin{tabular}{|c|c|c|c|c|c|c|c|c|c|c|c|c|c|c|c|c|}
\hline $\begin{array}{c}\text { Sub- } \\
\text { factor }\end{array}$ & \multicolumn{3}{|c|}{ C11 } & \multicolumn{3}{c|}{ C12 } & \multicolumn{3}{c|}{ C13 14} & \multicolumn{3}{c|}{ C15 } \\
\hline C11 & 1 & 1 & 1 & 0.6711 & 0.7914 & 0.9492 & 0.5514 & 0.6395 & 0.7481 & 0.6229 & 0.7241 & 0.8498 & 0.7969 & 0.9494 & 1.1166 \\
\hline C12 & 1.0535 & 1.2636 & 1.4901 & 1 & 1 & 1 & 0.6061 & 0.6977 & 0.8091 & 0.7748 & 0.8721 & 0.9930 & 0.9019 & 1.0616 & 1.2417 \\
\hline C13 & 1.3368 & 1.5637 & 1.8135 & 1.2360 & 1.4333 & 1.6499 & 1 & 1 & 1 & 0.7978 & 0.8900 & 0.9944 & 1.2979 & 1.5280 & 1.7720 \\
\hline C14 & 1.1768 & 1.3811 & 1.6054 & 1.0071 & 1.1467 & 1.2907 & 1.0057 & 1.1236 & 1.2534 & 1 & 1 & 1 & 1.2859 & 1.5184 & 1.7714 \\
\hline C15 & 0.8956 & 1.0533 & 1.2548 & 0.8054 & 0.9420 & 1.1088 & 0.5643 & 0.6545 & 0.7705 & 0.5645 & 0.6586 & 0.7777 & 1 & 1 & 1 \\
\hline
\end{tabular}

Table 6. Fuzzy comparison matrix $(3 \times 3)$ for sub-factors in level 2 (tractability branch)

\begin{tabular}{|c|c|c|c|c|c|c|c|c|c|}
\hline Sub-factor & \multicolumn{3}{|c|}{ C21 } & \multicolumn{3}{c|}{ C22 } & \multicolumn{3}{c|}{ C23 } \\
\hline C21 & 1 & 1 & 1 & 0.7714 & 0.8526 & 0.9552 & 0.3715 & 0.4180 & 0.4797 \\
\hline C22 & 1.0469 & 1.1729 & 1.2963 & 1 & 1 & 1 & 0.4625 & 0.5242 & 0.6037 \\
\hline C23 & 2.0847 & 2.3922 & 2.6918 & 1.6565 & 1.9077 & 2.1622 & 1 & 1 & 1 \\
\hline
\end{tabular}

Table 7. Fuzzy comparison matrix $(3 \times 3)$ for sub-factors in level 2 (transport quality branch)

\begin{tabular}{|c|c|c|c|c|c|c|c|c|c|}
\hline Sub-factor & \multicolumn{3}{|c|}{ C31 } & \multicolumn{3}{c|}{ C32 } & \multicolumn{3}{c|}{ C33 } \\
\hline C31 & 1 & 1 & 1 & 0.6128 & 0.6965 & 0.8029 & 0.7515 & 0.8520 & 0.9734 \\
\hline C32 & 1.2455 & 1.4358 & 1.6318 & 1 & 1 & 1 & 2.0985 & 2.4076 & 2.7341 \\
\hline C33 & 1.0273 & 1.1737 & 1.3307 & 0.3658 & 0.4153 & 0.4765 & 1 & 1 & 1 \\
\hline
\end{tabular}

Table 8 . Fuzzy comparison matrix $(3 \times 3)$ for sub-factors in level 2 (fare branch)

\begin{tabular}{|c|c|c|c|c|c|c|c|c|c|}
\hline Sub-factor & \multicolumn{3}{|c|}{ C41 } & \multicolumn{3}{c|}{ C42 } & \multicolumn{3}{c|}{ C43 } \\
\hline C41 & 1 & 1 & 1 & 0.7830 & 0.9300 & 1.0989 & 0.2866 & 0.3406 & 0.4101 \\
\hline C42 & 0.9100 & 1.0752 & 1.2772 & 1 & 1 & 1 & 0.4448 & 0.5070 & 0.5869 \\
\hline C43 & 2.4385 & 2.9363 & 3.4897 & 1.7037 & 1.9725 & 2.2482 & 1 & 1 & 1 \\
\hline
\end{tabular}

Table 9. Fuzzy comparison matrix $(3 \times 3)$ for sub-factors in level 3 (approachability branch)

\begin{tabular}{|c|c|c|c|c|c|c|c|c|c|}
\hline Sub-factor & \multicolumn{3}{|c|}{ C111 } & \multicolumn{3}{c|}{ C112 } & \multicolumn{3}{c|}{ C113 } \\
\hline C111 & 1 & 1 & 1 & 0.3702 & 0.4215 & 0.4820 & 0.9540 & 1.1336 & 1.3102 \\
\hline C112 & 2.0746 & 2.3724 & 2.7009 & 1 & 1 & 1 & 1.4276 & 1.7076 & 2.0122 \\
\hline C113 & 0.7632 & 0.8821 & 1.0482 & 0.4970 & 0.5856 & 0.7005 & 1 & 1 & 1 \\
\hline
\end{tabular}

Table 10. Fuzzy comparison matrix $(3 \times 3)$ for sub-factors in level 3 (speed branch)

\begin{tabular}{|c|c|c|c|c|c|c|c|c|c|}
\hline Sub-factor & \multicolumn{3}{|c|}{ C141 } & \multicolumn{3}{c|}{ C142 } & \multicolumn{3}{c|}{ C143 } \\
\hline C141 & 1 & 1 & 1 & 0.4585 & 0.5153 & 0.5936 & 0.6490 & 0.7379 & 0.8504 \\
\hline C142 & 1.6847 & 1.9404 & 2.1809 & 1 & 1 & 1 & 1.1199 & 1.2554 & 1.4012 \\
\hline C143 & 1.1759 & 1.3551 & 1.5407 & 0.7137 & 0.7966 & 0.8929 & 1 & 1 & 1 \\
\hline
\end{tabular}


Table 11. The final weight scores for public transport supply quality criteria

\begin{tabular}{|c|c|c|c|c|}
\hline Level & Criteria & Score & Rank & Global rank \\
\hline \multirow{4}{*}{ Level 1} & Service quality & 0.2701 & 2 & 2 \\
\hline & Transport quality & 0.3396 & 1 & 1 \\
\hline & Tractability & 0.1922 & 4 & 4 \\
\hline & Fare & 0.2141 & 3 & 3 \\
\hline \multirow{14}{*}{ Level 2} & Approachability & 0.0440 & 14 & 18 \\
\hline & Directness & 0.0520 & 10 & 14 \\
\hline & Time availability & 0.0675 & 6 & 10 \\
\hline & Speed & 0.0658 & 7 & 11 \\
\hline & Reliability & 0.0459 & 12 & 16 \\
\hline & Physical comfort & 0.0758 & 5 & 9 \\
\hline & Mental comfort & 0.0907 & 4 & 8 \\
\hline & Safety of travel & 0.1762 & 1 & 5 \\
\hline & Perspicuity & 0.0521 & 9 & 13 \\
\hline & Info before travel & 0.0933 & 3 & 7 \\
\hline & Info during travel & 0.0487 & 11 & 15 \\
\hline & One-way tickets & 0.0451 & 13 & 17 \\
\hline & $\begin{array}{l}\text { Weekly/monthly } \\
\text { tickets }\end{array}$ & 0.0540 & 8 & 12 \\
\hline & Discounted tickets & 0.1182 & 2 & 6 \\
\hline \multirow{10}{*}{ Level 3} & Distance to stop & 0.0109 & 10 & 28 \\
\hline & Comfort of Stops & 0.0223 & 5 & 23 \\
\hline & Safety of Stops & 0.0113 & 9 & 27 \\
\hline & Need for transfer & 0.0208 & 7 & 25 \\
\hline & Fit connection & 0.0312 & 2 & 20 \\
\hline & Frequency of lines & 0.0377 & 1 & 19 \\
\hline & Limited time of use & 0.0298 & 3 & 21 \\
\hline & Journey time & 0.0156 & 8 & 26 \\
\hline & Awaiting time & 0.0288 & 4 & 22 \\
\hline & Time to reach stops & 0.0220 & 6 & 24 \\
\hline
\end{tabular}

In the analysis, it has to be emphasized that all the scores reflect the current situation of the examined transportation system as the asked questions in the survey targeted the evaluation of different travel demand elements in PC related to the need of development. From travel demand perspective, a very significant issue is the price of travel. However, in this situation, as can be seen in the Table 11 of scores, fare has been only ranked third out of the level 1 elements. Consequently, the better utilization of the public vehicles does not depend on price reduction, currently the citizens consider the price of tickets affordable. Greater increase of public travels could be reached by improving transport quality elements, mainly the safety of travel (the highest ranked level 2 element).

Getting to the level 3, rescheduling of the timetable seems to be the best implication to raise the attractiveness of public transport. It is clearly indicated that from users' and potential users' perspective more frequent lines are required (certainly it has to be examined thoroughly, which specific lines should be more frequent) and more attention should be paid to the fit connection of buses or buses and trains. The awaiting time elements has also been criticized, which is a direct consequent of the less frequent lines and non-efficient connections of vehicles in the urban transport. One more specific element must be highlighted; the limited time of use of public lines is not satisfactory for the citizens. This is most likely due to the need for earlier first line in the morning in order to get to the workplace or school in time or might be the need for the last line in the evening to get back home by public lines.

Even though price of tickets has only been ranked third in the level 1 , on the second, possible discounted tickets element has been positioned in the second place. In FAHP, this is a very strong indication because the scores are computed by the multiplication of the respected higherlevel element in the hierarchy (please see Equation (10)). This means that although in general, the public is satisfied with the current transport price, discounted tickets for specific groups of the society, e.g. students, pensioners, public workers would be beneficial and might attract more people to use public vehicles. In contrast, the two other price elements: one-way tickets and weekly/monthly tickets have been evaluated much lower important, so the supply and price level of these issues do not need any modifications. The geographical positions, comfortability and reachability of stops are satisfactory, the participants ranked these issues very low so not significant need for improvement could be detected related to these elements of the transport system.

All in all, based on the results of the FAHP model, in the current situation most urgently the transport quality issues need improvement, especially the safety of travel on public vehicles. Possibly the training of public bus drivers and an overview on the technical status of buses could be efficient implications. In addition, it is advisable to reconsider the road safety regulations in the city or develop the condition of roads at least along the main public transport lines. Decision makers are also recommended to overview the schedules of the urban lines because both the frequency and time of usage were criticized by the public. Certainly, this is a very common requirement from the public and usually the government does not have to budget to finance all citizen requirements. Despite, it is suggested thinking over the modification of current timetables and conduct a cost-benefit analysis on more frequent lines or on expanded daily time frame of run for the local buses.

Regarding the fares, the only issue needs modification is the situation of discounted tickets. Local government should consider introducing lower price tickets (possibly weekly or monthly tickets) for specific groups of the society to attract more people to public transport.

\section{Conclusions}

In contrast with the traditional transport demand analysis methods, the introduced FAHP model provided more information on the specific elements of passenger preferences including the current price, however, less informa- 
tion on the quantity of travels. The cited general models (four-steps, discrete choice and activity-based) all perform better in quantity analysis and forecasting but the MCDM approach and within that the FAHP modelling is more capable of determining the crucial elements of passenger preferences.

Fuzzyfication has been proven to be successful based on the results, since the citizen evaluators were not fully aware of the importance proportions in the PCs, thus allowing more flexible numbers helped in gaining a more trustworthy scoring and ranking. The fuzzy approach can be suggested for all decision support cases in which layman participants evaluate the elements of the decision structure, mainly in those techniques in which PCs are applied. This consideration has been justified by our survey results. As a remark for further research, the combination of the general models and MCDM modelling is highly recommended. Mainly, a hybrid method of discrete choice and FAHP modelling would be very beneficial in order to integrate the advantages of both approaches. Discrete choice might determine the connections of public travel price and quantified demand while FAHP might analyse the demand elements and the linkage between current pricing and quality issues of the transport system. It is also possible to bound MCDM with activity-based models in which the intentions of the public generate the demand determination and these intentions can be analysed by FAHP or other MCDM support techniques.

Practically, the demonstrated procedure is considered as knowledge acquisition from the public related to quality and fare system development of the current public bus transport situation of the examined city. The model, survey procedure and the analysis can be applied to arbitrary urban transport development initiations for collecting the data referring preferences of the citizens. This can be considered as the main contribution of this research.

As limitation of the recent survey, it has to be emphasized that the generally applied WTP approach has not been examined by the introduced FAHP model. WTP reflects the motivation of the citizens for paying the public transport fare in different scenarios, thus it is a valuable indicator of public demand. Integrating the WTP factor to the model is a subject of future research.

Definitely, the mixture of quantitative and decision support methods possesses huge potential in forecasting and analysis of travel demand not only in theory but also in practice of transportation management.

\section{Author contributions}

Ahmad Alkharabsheh and Sarbast Moslem were responsible for data collection and analysis. Ahmad Alkharabsheh, Sarbast Moslem and Szabolcs Duleba were responsible for data interpretation.

Szabolcs Duleba was responsible for conceptualization and final analysis.

In paper writing, all authors were participated.

\section{Disclosure statement}

The authors declare that they have not any competing financial, professional, or personal interests from other parties.

\section{References}

Abastante, F.; Corrente, S.; Greco, S.; Ishizaka, A.; Lami, I. M. 2018. Choice architecture for architecture choices: evaluating social housing initiatives putting together a parsimonious AHP methodology and the Choquet integral, Land Use Policy 78: 748-762. https://doi.org/10.1016/j.landusepol.2018.07.037

Arslan, T. 2009. A hybrid model of fuzzy and AHP for handling public assessments on transportation projects, Transportation 36(1): 97-112. https://doi.org/10.1007/s11116-008-9181-9

Balaji, M.; Santhanakrishnan, S.; Dinesh, S. N. 2019. An application of analytic hierarchy process in vehicle routing problem. Periodica Polytechnica Transportation Engineering 47(3): 196-205. https://doi.org/10.3311/PPtr.10701

Bhat, C. R. 2018. A new flexible multiple discrete-continuous extreme value (MDCEV) choice model, Transportation Research Part B: Methodological 110: 261-279. https://doi.org/10.1016/j.trb.2018.02.011

Bilişik, Ö. N.; Erdoğan, M.; Kaya, İ.; Baraçl1, H. 2013. A hybrid fuzzy methodology to evaluate customer satisfaction in a public transportation system for Istanbul, Total Quality Management \& Business Excellence 24(9-10): 1141-1159. https://doi.org/10.1080/14783363.2013.809942

Bowman, J. L.; Ben-Akiva, M. E. 2001. Activity-based disaggregate travel demand model system with activity schedules, Transportation Research Part A: Policy and Practice 35(1): 1-28. https://doi.org/10.1016/S0965-8564(99)00043-9

Chen, Y.; Wang, S.; Yao, J.; Li, Y.; Yang, S. 2018. Socially responsible supplier selection and sustainable supply chain development: a combined approach of total interpretive structural modeling and fuzzy analytic network process, Business Strategy and the Environment 27(8): 1708-1719. https://doi.org/10.1002/bse.2236

Chiou, Y.-C.; Chen, Y.-H. 2012. Service quality effects on air passenger intentions: a service chain perspective, Transportmetrica 8(6): 406-426.

https://doi.org/10.1080/18128602.2010.548837

Chowdhury, S.; Hadas, Y.; Gonzalez, V. A.; Schot, B. 2018. Public transport users' and policy makers' perceptions of integrated public transport systems, Transport Policy 61: 75-83. https://doi.org/10.1016/j.tranpol.2017.10.001

Del Castillo, J. M.; Benitez, F. G. 2012. A methodology for modeling and identifying users satisfaction issues in public transport systems based on users surveys, Procedia - Social and Behavioral Sciences 54: 1104-1114. https://doi.org/10.1016/j.sbspro.2012.09.825

DoS. 2017. Statistical Yearbook of Jordan 2017. Department of Statistics (DoS), Amman, Jordan. 324 p. Available from Internet: http://dosweb.dos.gov.jo/databank/Yearbook2017/ YearBook2017.pdf

Duleba, S.; Mishina, T.; Shimazaki, Y. 2012. A dynamic analysis on public bus transport's supply quality by using AHP, Transport 27(3): 268-275. https://doi.org/10.3846/16484142.2012.719838

Duleba, S.; Moslem, S. 2018. Sustainable urban transport development with stakeholder participation, an AHP-Kendall model: a case study for Mersin, Sustainability 10(10): 3647. https://doi.org/10.3390/su10103647 
Duleba, S.; Shimazaki, Y.; Mishina, T. 2013. An analysis on the connections of factors in a public transport system by AHPISM, Transport 28(4): 404-412.

https://doi.org/10.3846/16484142.2013.867282

Eboli, L.; Mazzulla, G. 2008. A stated preference experiment for measuring service quality in public transport, Transportation Planning and Technology 31(5): 509-523.

https://doi.org/10.1080/03081060802364471

Eboli, L.; Mazzulla, G. 2007. Service quality attributes affecting customer satisfaction for bus transit, Journal of Public Transportation 10(3): 21-34.

https://doi.org/10.5038/2375-0901.10.3.2

Farooq, D.; Moslem, S.; Duleba, S. 2019. Evaluation of driver behavior criteria for evolution of sustainable traffic safety, Sustainability 11(11): 3142. https://doi.org/10.3390/su11113142

GAM. 2010. Transport and Mobility Master Plan for Amman. Final Report. Greater Amman Municipality (GAM), Amman, Jordan. 156 p. Available from Internet: http://www.ammanbrt.jo/contents/Articles/2020/4/20/\%D8\%A7\%D9\%84\%D9\% 85\%D8\%AE\%D8\%B7\%D8\%B7\%D8\%A7\%D9\%84\%D8\%B4 \%D9\%85\%D9\%88\%D9\%84\%D9\%8A\%D9\%84\%D9\%84\%D9 \%86\%D9\%82\%D9\%84\%D9\%88\%D8\%A7\%D9\%84\%D8\%AD \%D8\%B1\%D9\%83\%D9\%87\%D9\%81\%D9\%8A\%D9\%85\%D8 \%AF\%D9\%8A\%D9\%86\%D8\%A9\%D8\%B9\%D9\%85\%D8\%A 7\%D9\%86160322.pdf

Gao, T.; Na, S.; Dang, X.; Zhang, Y. 2018. Study of the competitiveness of Quanzhou port on the belt and road in China based on a fuzzy-AHP and ELECTRE III model, Sustainability 10(4): 1253. https://doi.org/10.3390/su10041253

Ghorbanzadeh, O.; Moslem, S.; Blaschke, T.; Duleba, S. 2019. Sustainable urban transport planning considering different stakeholder groups by an interval-AHP decision support model, Sustainability 11(1): 9.

https://doi.org/10.3390/su11010009

Grošelj, P.; Zadnik Stirn, L. 2018. Evaluation of several approaches for deriving weights in fuzzy group analytic hierarchy process, Journal of Decision Systems 27(suppl 1): 217-226. https://doi.org/10.1080/12460125.2018.1460160

Gupta, V. 2018. Comparative performance of contradictory and non-contradictory judgement matrices in AHP under qualitative and quantitative metrics, International Journal of Decision Support System Technology 10(1): 21-38.

https://doi.org/10.4018/IJDSST.2018010102

Haghighathoseini, A.; Bobarshad, H.; Saghafi, F.; Rezaei, M. S.; Bagherzadeh, N. 2018. Hospital enterprise architecture framework (study of Iranian university hospital organization), International Journal of Medical Informatics 114: 88100. https://doi.org/10.1016/j.ijmedinf.2018.03.009

Hasnine, M. S.; Habib, K. N. 2018. What about the dynamics in daily travel mode choices? A dynamic discrete choice approach for tour-based mode choice modelling, Transport Policy 71: 70-80. https://doi.org/10.1016/j.tranpol.2018.07.011

Hatefi, S. M.; Tamošaitiene, J. 2018. Construction projects assessment based on the sustainable development criteria by an integrated fuzzy AHP and improved GRA model, Sustainability 10(4): 991. https://doi.org/10.3390/su10040991

Hine, J.; Scott, J. 2000. Seamless, accessible travel: users' views of the public transport journey and interchange, Transport Policy 7(3): 217-226. https://doi.org/10.1016/S0967-070X(00)00022-6

Hsieh, T.-Y.; Lu, S.-T.; Tzeng, G.-H. 2004. Fuzzy MCDM approach for planning and design tenders selection in public office buildings, International Journal of Project Management 22(7): 573-584. https://doi.org/10.1016/j.ijproman.2004.01.002
Imam, R. 2014. Measuring public transport satisfaction from user surveys, International Journal of Business and Management 9(6): 106-114. https://doi.org/10.5539/ijbm.v9n6p106

John, A.; Yang, Z.; Riahi, R.; Wang, J. 2014. Application of a collaborative modelling and strategic fuzzy decision support system for selecting appropriate resilience strategies for seaport operations, Journal of Traffic and Transportation Engineering (English Edition) 1(3): 159-179.

https://doi.org/10.1016/S2095-7564(15)30101-X

Kumar, A.; Pal, A.; Vohra, A.; Gupta, S.; Manchanda, S.; Dash, M. K. 2018. Construction of capital procurement decision making model to optimize supplier selection using fuzzy Delphi and AHP-DEMATEL, Benchmarking: an International Journal 25(5): 1528-1547. https://doi.org/10.1108/BIJ-01-2017-0005

Lai, W.-T.; Chen, C.-F. 2011. Behavioral intentions of public transit passengers - the roles of service quality, perceived value, satisfaction and involvement, Transport Policy 18(2): 318-325. https://doi.org/10.1016/j.tranpol.2010.09.003

Liou, J. J. H.; Chuang, M.-L. 2010. Evaluating corporate image and reputation using fuzzy MCDM approach in airline market, Quality \& Quantity 44(6): 1079-1091. https://doi.org/10.1007/s11135-009-9259-2

Liou, J. J. H.; Yen, L.; Tzeng, G.-H. 2008. Building an effective safety management system for airlines, Journal of Air Transport Management 14(1): 20-26.

https://doi.org/10.1016/j.jairtraman.2007.10.002

Lirn, T.-C.; Thanopoulou, H. A.; Beresford, A. K. C. 2003. Transhipment port selection and decision-making behaviour: analysing the Taiwanese case, International Journal of Logistics Research and Applications: a Leading Journal of Supply Chain Management 6(4): 229-244.

https://doi.org/10.1080/13675560310001626990

Lupo, T. 2013. Handling stakeholder uncertain judgments in strategic transport service analyses, Transport Policy 29: 5463. https://doi.org/10.1016/j.tranpol.2013.04.002

McNally, M. G. 2007. The four-step model, in D. A. Hensher, K. J. Button (Ed.). Handbook of Transport Modelling 1: 35-53. https://doi.org/10.1108/9780857245670-003

Mokonyama, M.; Venter, C. 2013. Incorporation of customer satisfaction in public transport contracts - a preliminary analysis, Research in Transportation Economics 39(1): 58-66. https://doi.org/10.1016/j.retrec.2012.05.024

Moslem, S.; Duleba, S. 2019. Sustainable urban transport development by applying a fuzzy-AHP model: a case study from Mersin, Turkey, Urban Science 3(2): 55.

https://doi.org/10.3390/urbansci3020055

Moslem, S.; Ghorbanzadeh, O.; Blaschke, T.; Duleba, S. 2019. Analysing stakeholder consensus for a sustainable transport development decision by the fuzzy AHP and interval AHP, Sustainability 11(12): 3271.

https://doi.org/10.3390/su11123271

Murat, Y. S.; Arslan, T.; Cakici, Z.; Akçam, C. 2016. Analytical hierarchy process (AHP) based decision support system for urban intersections in transportation planning, in E. V. Ocalir-Akunal (Ed.). Using Decision Support Systems for Transportation Planning Efficiency, 203-222.

https://doi.org/10.4018/978-1-4666-8648-9.ch008

Ngossaha, J. M.; Ngouna, R. H.; Archimède, B.; Nlong, J. M. 2017. Sustainability assessment of a transportation system under uncertainty: an integrated multicriteria approach, IFACPapersOnLine 50(1): 7481-7486.

https://doi.org/10.1016/j.ifacol.2017.08.1064

Pantouvakis, A.; Lymperopoulos, K. 2008. Customer satisfaction and loyalty in the eyes of new and repeat customers: evidence 
from the transport sector, Managing Service Quality: an International Journal 18(6): 623-643.

https://doi.org/10.1108/09604520810920103

Paquette, J.; Bellavance, F.; Cordeau, J. F.; Laporte, G. 2012. Measuring quality of service in dial-a-ride operations: the case of a Canadian city, Transportation 39(3): 539-564. https://doi.org/10.1007/s11116-011-9375-4

Park, K.-S.; Seo, Y.-J.; Kim, A.-R.; Ha, M.-H. 2018. Ship acquisition of shipping companies by sale \& purchase activities for sustainable growth: exploratory fuzzy-AHP application, Sustainability 10(6): 1763. https://doi.org/10.3390/su10061763

Pendyala, R. M.; Kitamura, R.; Kikuchi, A.; Yamamoto, T.; Fujii, S. 2005. Florida activity mobility simulator: overview and preliminary validation results, Transportation Research Record: Journal of the Transportation Research Board 1921: 123-130. https://doi.org/10.1177/0361198105192100114

Rasouli, S.; Timmermans, H. 2012. Uncertainty in travel demand forecasting models: literature review and research agenda, Transportation Letters: the International Journal of Transportation Research 4(1): 55-73. https://doi.org/10.3328/TL.2012.04.01.55-73

Redman, L.; Friman, M.; Gärling, T.; Hartig, T. 2013. Quality attributes of public transport that attract car users: a research review, Transport Policy 25: 119-127. https://doi.org/10.1016/j.tranpol.2012.11.005

Rohani, M. M.; Wijeyesekera, D. C.; Karim, A. T. A. 2013. Bus operation, quality service and the role of bus provider and driver, Procedia Engineering 53: 167-178.

https://doi.org/10.1016/j.proeng.2013.02.022

Ruiz-Padillo, A.; Pasqual, F. M.; Larranaga Uriarte, A. M.; Bettella Cybis, H. B. 2018. Application of multi-criteria decision analysis methods for assessing walkability: a case study in Porto Alegre, Brazil, Transportation Research Part D: Transport and Environment 63: 855-871.

https://doi.org/10.1016/j.trd.2018.07.016

Saaty, T. L. 1977. A scaling method for priorities in hierarchical structures, Journal of Mathematical Psychology 15(3): 234281. https://doi.org/10.1016/0022-2496(77)90033-5

Saaty, T. L. 1980. The Analytic Hierarchy Process. McGraw-Hill.

Sun, C.-C. 2010. A performance evaluation model by integrating fuzzy AHP and fuzzy TOPSIS methods, Expert Systems with Applications 37(12): 7745-7754.

https://doi.org/10.1016/j.eswa.2010.04.066

Tan, R. R.; Aviso, K. B.; Huelgas, A. P.; Promentilla, M. A. B. 2014. Fuzzy AHP approach to selection problems in process engineering involving quantitative and qualitative aspects, Process Safety and Environmental Protection 92(5): 467-475. https://doi.org/10.1016/j.psep.2013.11.005

Taskin Gumus, A. 2009. Evaluation of hazardous waste transportation firms by using a two step fuzzy-AHP and TOPSIS methodology, Expert Systems with Applications 36(2): 40674074. https://doi.org/10.1016/j.eswa.2008.03.013

Teng, J.-Y.; Huang, W.-C.; Lin, M.-C. 2010. Systematic budget allocation for transportation construction projects: a case in Taiwan, Transportation 37(2): 331-361. https://doi.org/10.1007/s11116-009-9239-3

Yayla, A. Y.; Oztekin, A.; Gumus, A. T.; Gunasekaran, A. 2015. A hybrid data analytic methodology for 3PL transportation provider evaluation using fuzzy multi-criteria decision making, International Journal of Production Research 53(20): 6097-6113. https://doi.org/10.1080/00207543.2015.1022266 